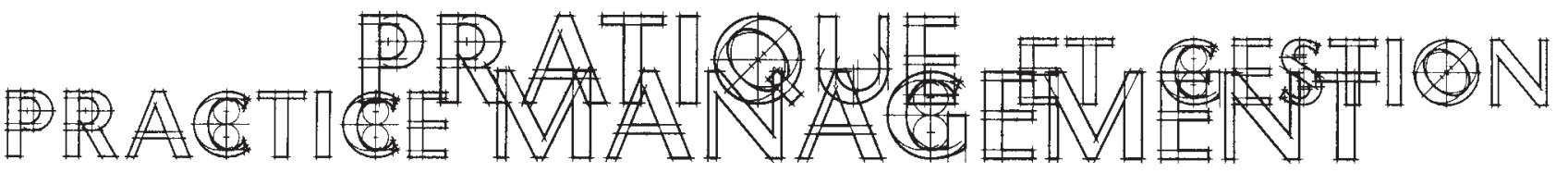

\title{
Private Practice and Corporate Optometry Compared
}

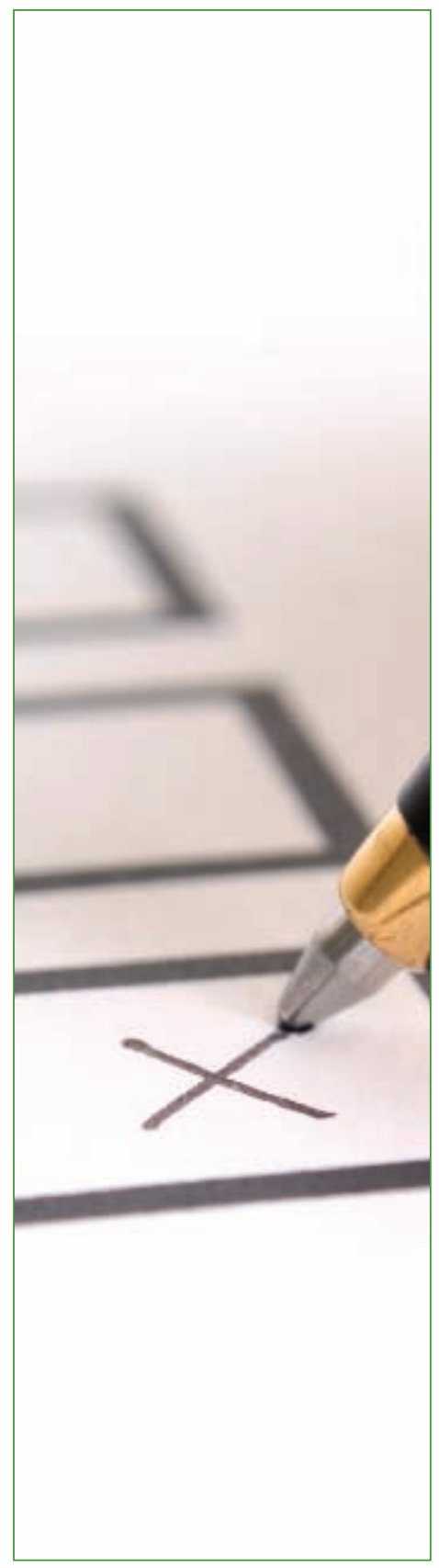

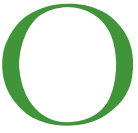

ptometrists today are fortunate to have various types of employment opportunities to choose from. Along with the traditional private practice there are corporate practices, laser clinics, research and teaching. The private setting is still the preferred mode of practice but as time goes on, more doctors are choosing the corporate option. Nearly half of new graduates from U.S. schools are going into corporate optometry to start their professional career.

Several business arrangements are available in the corporate setting. As a franchise, the doctor owns the professional practice and runs it as a completely independent business. The doctor may sub-lease his space from the optical corporation and again operate as an independent business. An optometrist may work as an independent contractor for the corporate entity where they are paid for their time or by the number of patients they see, or the optometrist may simply be employed by the optical.

The attraction for working in a corporate environment is the higher starting salary compared to that offered to an associate in private practice. New graduates finish their education with a high debt load, estimated at anywhere from $\$ 100,000$ to $\$ 200,000$ (US data). The ability to make a high salary with no risk and no capital start-up costs while allowing the doctor to pay down their debt is difficult to resist. The marketing power of the optical, which is typically located in a high traffic area, provides an immediate busy practice for the doctor.

When asked, many doctors who enter the corporate practice say they see this as a stepping stone towards their ultimate goal of private practice. They want to reduce their debt load and be certain they like working in the area before moving to private practice. Doctors in private practice should keep this in mind when searching for new associates or partners.

Many doctors find the general working environment in a corporate practice appealing as they can spend most of their time on patient care. Management issues, and headaches,

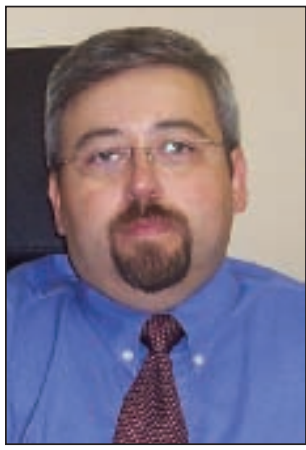

Alphonse Carew $\mathrm{BSC}, \mathrm{OD}, \mathrm{MBA}$ 


\section{PRACTICE MANAGEMENT

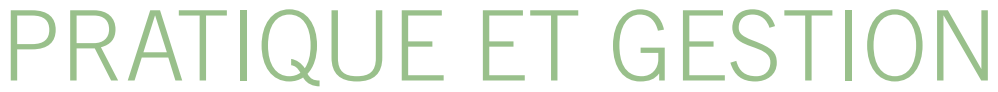

found in the traditional practice are handled by others. With that said, the optometrist has to realize that they have little say in the future direction of the corporate entity and major decisions are made by business people who do not have patient care as their number one priority.

In comparison, private practice can involve taking more risks but also reap higher rewards. The cost to start in private practice is usually higher than the corporate setting, whether you consider the initial lower salary usually provided to associates in private practice, or the actual cost to set-up a practice cold. Numerous details need to be managed, including accounting, IT, suppliers, human resource, and marketing, to name a few. At first glance it's easy to see why new graduates would gravitate towards the corporate world. However, this is only the short-term view of things. To get the whole picture one needs to look long term.

Even though the starting salary is typically higher in the corporate setting, on average the salary made by these doctors is approximately $\$ 99,000$ (all data from U.S. sources) while those in private practice make about $\$ 135,000$. Over a lifetime, the optometrist in private practice would make more. A solo-practitioner in either corporate, or private practice is limited by the amount of work that can be done by one doctor, the added benefit in the private practice is the net income from the in-house optical, owned by the doctor, adds to their income.

However, this doesn't tell the whole story, doctors in a group private practice setting ( 3 or more doctors) tend to make the most overall at over $\$ 177,000$, these are the healthiest optometrists, financially. The benefit of having a group practice in a corporate setting is not nearly as strong. A doctor presently in a corporate practice who decides to add a doctor will end up paying a large

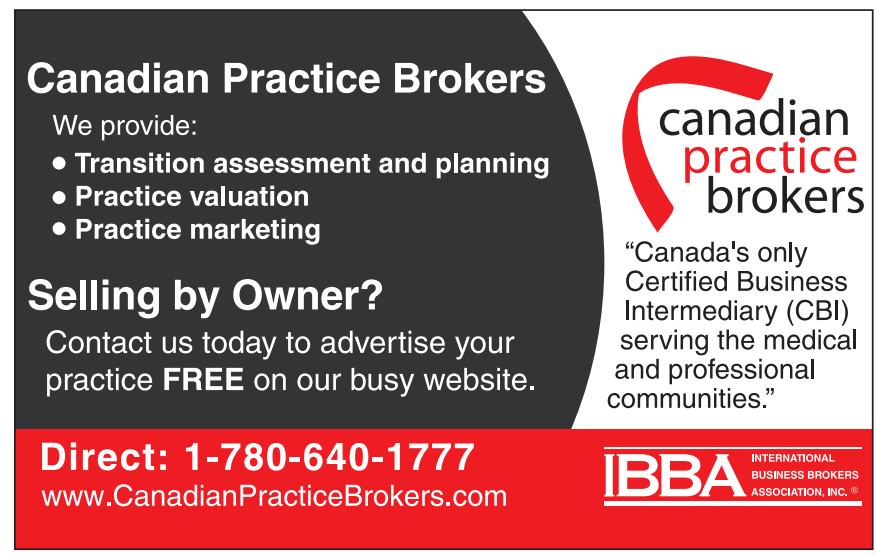

percentage of the revenue generate by that associate back to the associate as salary. There is less benefit to hiring the doctor especially if added costs (like staff salaries) have to be incurred. In general, expansion can be difficult in the corporate setting as securing space for more exam rooms and equipment may be impossible.

The final piece of the puzzle in the comparison involves the value the practice has when the doctor finally leaves. In the corporate practice, the doctor may simply leave and not realize any financial gain from the years of service. If the doctor has been running it as a franchise or in a sublease arrangement then he, or she, may have some equity to sell to another doctor or to move into a private setting. However, even then, the value of the practice will be less than a private practice because the gross revenue and net incomes are less.

In private practice there is generally a greater chance of realizing a financial gain from the equity built up in the practice over the years. These practices are easier to evaluate and banks are more apt to provide financing as they are familiar with these entities.

Corporate optometry provides a valuable service to the public as well as providing working opportunities for optometrists, especially those wishing a risk and worry-free environment. Many find it a helpful stepping stone from graduation into private practice. In the long run, private practice, especially group practice, provides the best financial situation, although it can come at a price. One has to be comfortable with risk and up to the challenge of managing a small business. Those looking to expand their private practice should look to doctors presently working in the corporate environment. It could be a win-win for both parties.

\section{PAR-MED PROPERTY SERVICES INC.}

PAR-Med is the recognized leader in property management of medical office buildings in Ontario. Opportunities exist within our portfolio for optometry services and dispensing.

TELEPHONE 416-364-5959 x403 1-800-663-5340 EMAIL: info@par-med.com www.par-med.com 